\title{
Effect of Top Reinforcing on the Fire Performance of Continuous Reinforced Concrete Beams
}

\author{
DANIELA BERNHART ${ }^{1}$, ANDREW BUCHANAN $^{2}$, RAJESH DHAKAL $^{2}$, and \\ PETER MOSS ${ }^{2}$ \\ ${ }^{1}$ University of Karlsruhe \\ Karlsruhe, Germany \\ ${ }^{2}$ University of Canterbury \\ Christchurch, New Zealand
}

\begin{abstract}
This paper examines the behaviour of continuous reinforced concrete beams exposed to fire on three sides, in order to investigate the effect of different lengths of the top reinforcing bars over the supports. The study was performed with 2D finite element analysis using SAFIR. The effect of continuity was investigated with rectangular crosssection beams spanning over two and three bays subjected to the ISO 834 fire. Compared to a single span beam, the continuous beams resisted the fire exposure for a longer period of time. It was found that different lengths of the top reinforcing bars resulted in different failure mechanisms, but did not greatly affect the fire resistance of the beams. The influence of the full process of fire development was analysed using the ISO fire for 30, 60 and 90 minutes followed by a decay phase. Structural failure only occurred if the fully developed phase of the fire continued until very close to the failure time reached with no decay phase.
\end{abstract}

KEYWORDS: numerical analysis, structural response, reinforced concrete, continuous beams, restraint

\section{INTRODUCTION}

Concrete frame structures form the basis of most modern multi-storey buildings. Concrete structures have a reputation of very good behaviour in fire conditions as not many fires have ever led to collapse of a properly designed concrete structure. One of the main types of structural elements within concrete structures are the beams. As the beams form the supports for other load-bearing elements like slabs, their collapse during a fire can be detrimental to the stability of the rest of the structure.

The behaviour of concrete beams in fires is complex, because thermal and load induced stresses are combined as the beam deforms. The most obvious consequence of a fire is the degradation in strength of the concrete and the reinforcing steel. Heating of a beam is accompanied by thermal expansion, resulting in bowing deformations and an increase in length. Depending on the support details, axial expansion may cause the surrounding structure to impose high axial forces which are not normally included in the design process [Buchanan, 1]. This paper is a summary of an extensive study by Bernhart [2].

\section{Code Recommendations}

Eurocode 2 Part 1-2 [3,4] deals with the design of concrete structures for fire situations and gives three alternative methods for determining adequate fire ratings. 
Tabulated data: These give minimum values for the cross-sectional dimensions and the concrete cover distances to the longitudinal reinforcement. For beams there is a distinction between simply-supported and continuous beams.

Simplified calculation methods for specific types of members: These calculation methods are for assessing the strength of the concrete members after any time of exposure to the standard fire. These methods are based on a reduced cross-section consisting of the cooler parts of the member, so the temperature profiles within the member and the temperature dependent material properties are needed.

Advanced calculation methods: These can be used for the simulation of the structural behaviour of single members, parts of the structure, or the entire structure, exposed to any type of fire exposure. These methods are based on fundamental physical behaviour leading to a reliable approximation of the expected behaviour under fire conditions. The code provides data including thermal and mechanical properties of concrete and reinforcing steel subjected to elevated temperatures.

The German regulations for fire resistance of concrete structures are described in DIN 4102-4 [5] which gives tabulated data for the size of the member, the axial distance of the longitudinal reinforcement to the concrete surface and the minimum number of reinforcing bars, all related to the fire resistance rating.

At present, DIN 4102-4 is not applicable to the current German concrete standard DIN 1045-1 [6], as it is based on stress analysis and not on the partial safety coefficient concept. This discrepancy is going to be addressed in DIN 4102-22 [7], which will give guidance for use of DIN 4102-4, but will not result in great changes in the use of the tabulated data for concrete beams. At the moment, the fire resistance can be determined using the tabulated data of Eurocode 2, with additional regulations as stated in Reference [8].

\section{Design Methods}

\section{Simplified Calculation Methods}

The design of beams under fire conditions is normally performed in the strength domain. Thus it has to be demonstrated that the load capacity is greater than the imposed loads at the required duration of fire exposure.

Eurocode 2 [3] gives two methods to determine the residual strength of a structural member using reduced cross-sections: The " $500^{\circ} \mathrm{C}$ isotherm method" reduces the crosssection size by a heat-damaged zone where the temperature exceeds $500^{\circ} \mathrm{C}$, and the ultimate load bearing capacity can be determined using the reduced strength of the reinforcing bars, as described in Eurocode 2 [3], CRSI [9], Harmathy [10], or the ACI Committee [11]. The "Zone method" subdivides the cross-section into several zones of equivalent thickness and evaluates the reduced strength of each zone. This method is more accurate, but more laborious than the $500^{\circ} \mathrm{C}$ isotherm method.

Temperature contours have been published among others by FIP [12], ACI [11], Wade [13] and the Eurocode [3,4] for standard fires. For fire conditions other than standard fires, the temperature profiles should be determined using suitable computer programs. 


\section{ANALYSES}

The cross-section of the beam used in the analyses is $300 \times 600 \mathrm{~mm}$ with bars laid out as shown in Fig. 1. The axis distance of the reinforcing bars to the concrete surface is $35 \mathrm{~mm}$ at the bottom and top, and $45 \mathrm{~mm}$ at the sides. The concrete has compressive strength of $30 \mathrm{~N} / \mathrm{mm}^{2}$ and zero tensile strength, with thermal and mechanical properties assumed to be that of siliceous aggregate from Eurocode 2. The reinforcing is $16 \mathrm{~mm}$ diameter bars with yield strength of $500 \mathrm{~N} / \mathrm{mm}^{2}$. The beams were designed to resist typical load combinations, for a span (or multiple spans) of 6.0 metres.

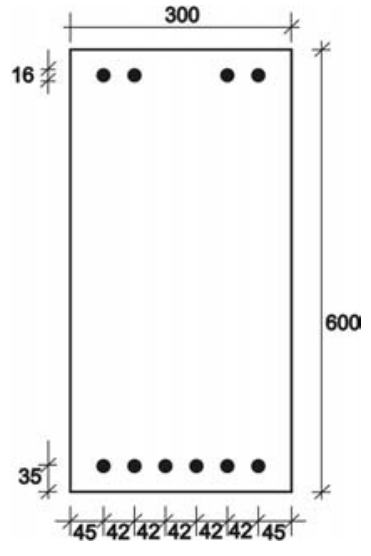

Fig. 1. Beam geometry.

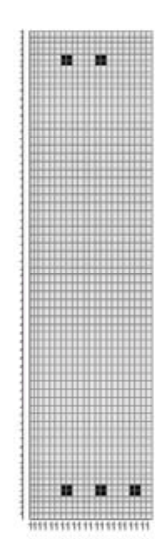

Fig. 2. SAFIR Discretisation of beam cross-section.

\section{SIMULATION MODELS}

\section{Description of the SAFIR Program}

SAFIR [14] is a special purpose 2D or 3D finite element program for analyzing structures at ambient or elevated temperatures. Only 2D beam elements are used in this study. The thermal and mechanical properties of steel and concrete follow the Eurocodes $[15,1]$ but user-defined materials can also be used for the thermal or structural analysis. The effect of concrete spalling cannot be modeled in the analysis, nor can shear behavior. Full composite action is assumed between the concrete and the reinforcing steel, and slip between the materials cannot be accounted for.

\section{Thermal Analysis}

The finite element discretisation of the half cross-section is shown in Fig. 2, being very fine in order to determine the temperatures at the centre of the reinforcing steel bars which are calculated at the nodes of the mesh. The beam is exposed to the ISO-fire timetemperature curve on three sides for four hours. Analysis with a decay phase is described later. The resulting temperature distribution is shown in Fig. 3. It can be seen that the reinforcing bars do not have great influence on the temperature distribution. 

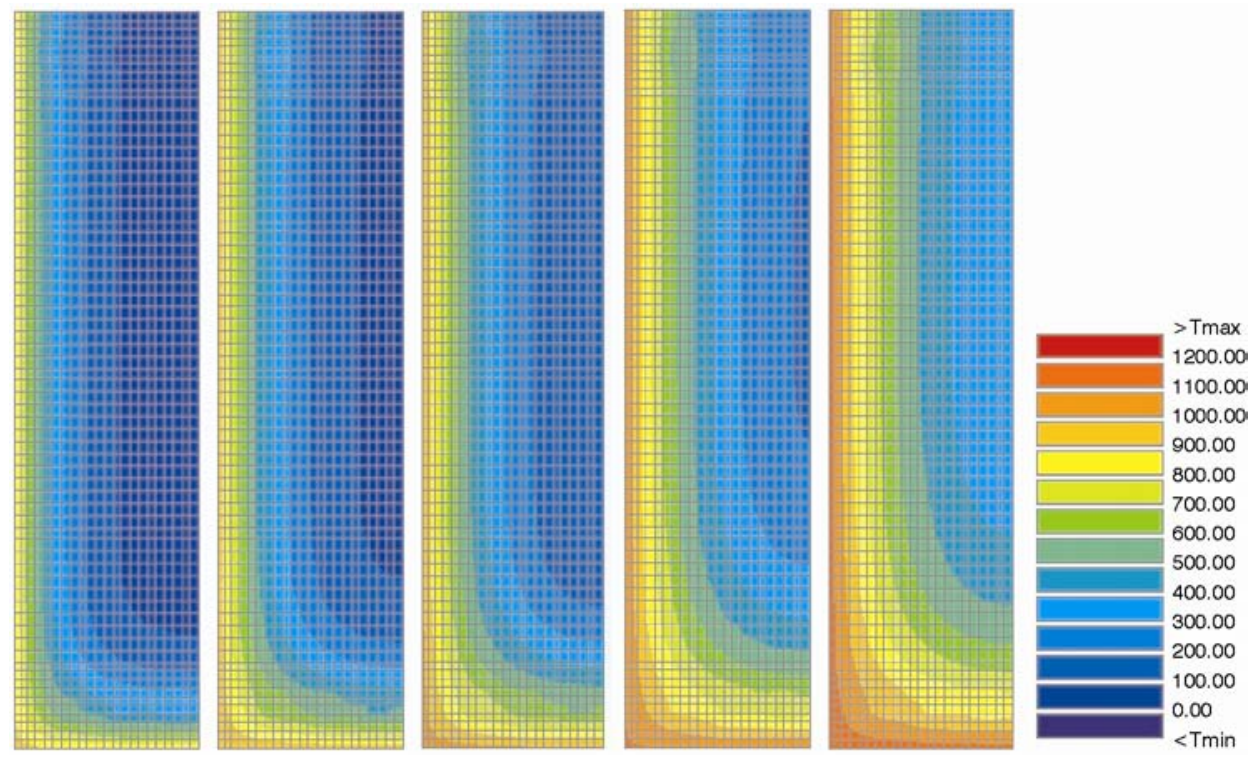

Fig. 3. Temperature profiles in the cross-section at $60 \mathrm{~min}, 90 \mathrm{~min}, 120 \mathrm{~min}, 180 \mathrm{~min}, 240 \mathrm{~min}$. Temperatures in ${ }^{\circ} \mathrm{C}$.
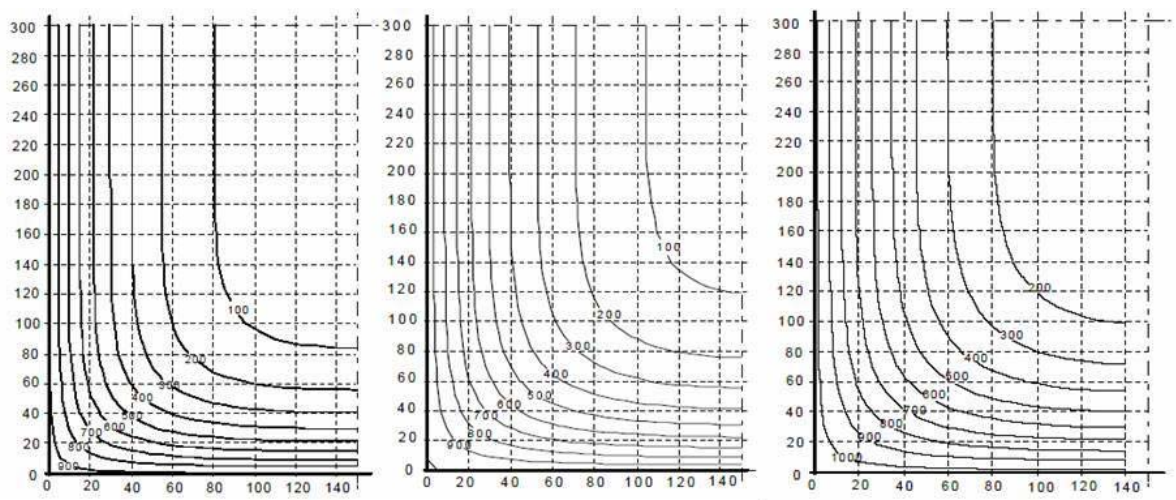

Fig. 4. Temperature distribution according to EC2 at $60 \mathrm{~min}$, $90 \mathrm{~min}$ and $120 \mathrm{~min}$.

For comparison, the tabulated temperature curves from Eurocode 2 are plotted in Fig. 4. The Eurocode temperatures are always slightly higher than the SAFIR predictions in the outer layers of the beam (though the Eurocode thermal and material properties were used in the analyses), but SAFIR predicted a somewhat faster increase in temperature at the core of the cross-section. The temperature development in the individual reinforcing bars is shown in Fig. 5 where, as expected, the bars closest to the surface show the steepest increase in temperature. After 120 minutes, the calculated temperatures are slightly higher than the data from Fig. 4 (shown by the crosses in Fig. 5) for bar 2 and the top bars. 


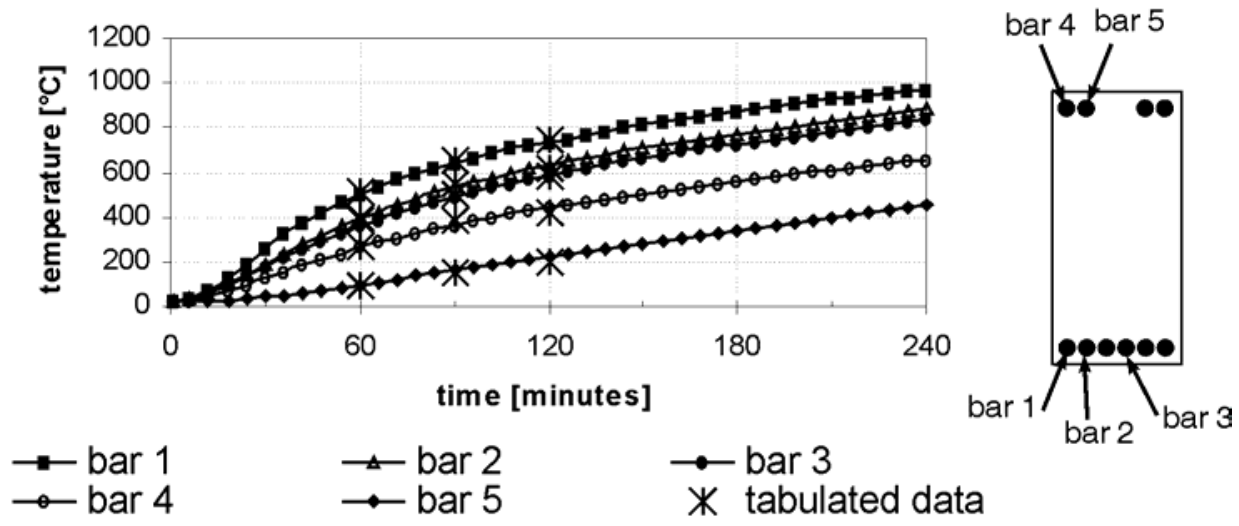

Fig. 5. Temperature distribution in the reinforcing bars.

\section{RESULTS OF COMPUTER ANALYSIS}

This section discusses the analysis of a reinforced concrete beam which is continuous over one support (see Fig. 6). Both bays of the beam are exposed to fire. Only one support is horizontally restrained, with the other supports free to move longitudinally. The purpose of this analysis is to investigate the effect of continuity at the centre support and the influence of different lengths of reinforcing bars in the top of the beam. In all cases the bottom reinforcement is continuous through the beam and has not been curtailed. The development length of the reinforcing bars needed for normal structural design has not been included in the computer model, because SAFIR assumes that perfect bond exists between the steel bars and the concrete.

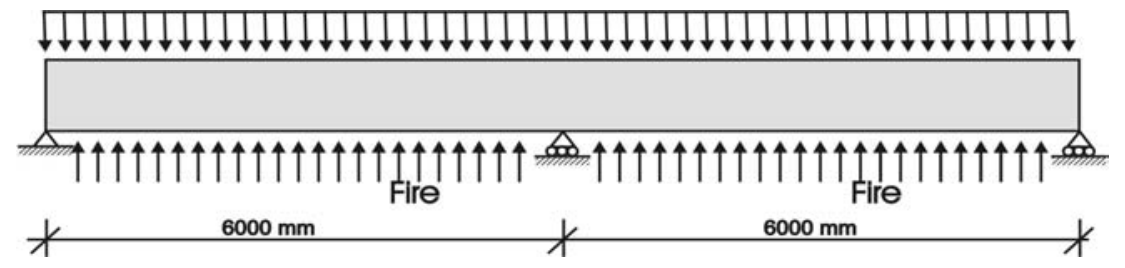

Fig. 6. General view of the continuous two-bay beam.

The analysis covers three different arrangements of top reinforcing. Beam 1 (Fig. 7) is designed according to DIN 1045-1 ignoring the possibility of fire. Beam 2 (Fig. 8) is also designed according to DIN 1045-1 but the top bars at the centre support have been lengthened in accordance with the Eurocode 2 design rules for fire conditions. Beam 3 (Fig. 9) follows the design rules of Reference [5] which requires the top bars over the supports to be elongated by $0.15 l_{\text {eff }}$ compared with Beam 1 . 


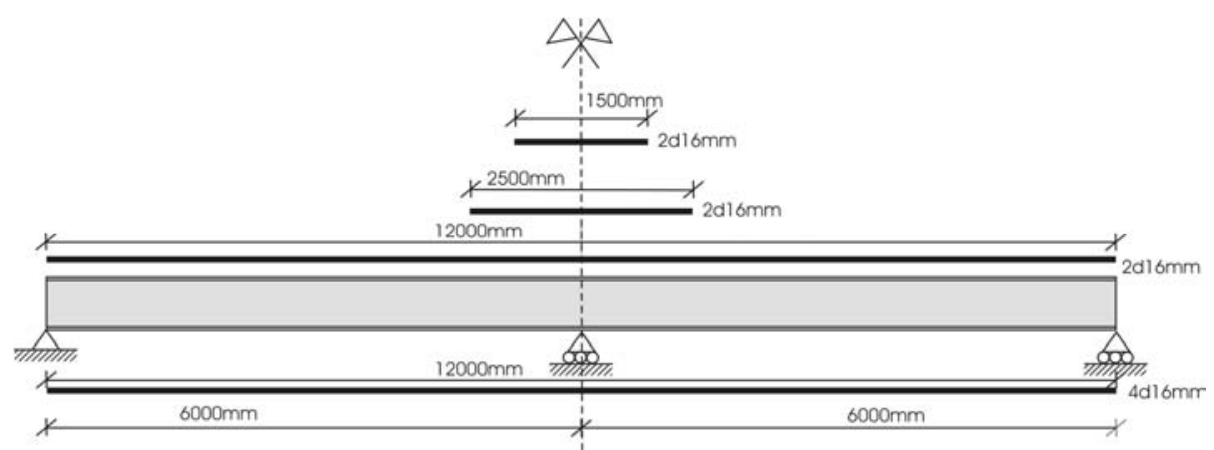

Fig. 7. Arrangement of reinforcing bars for Beam 1.

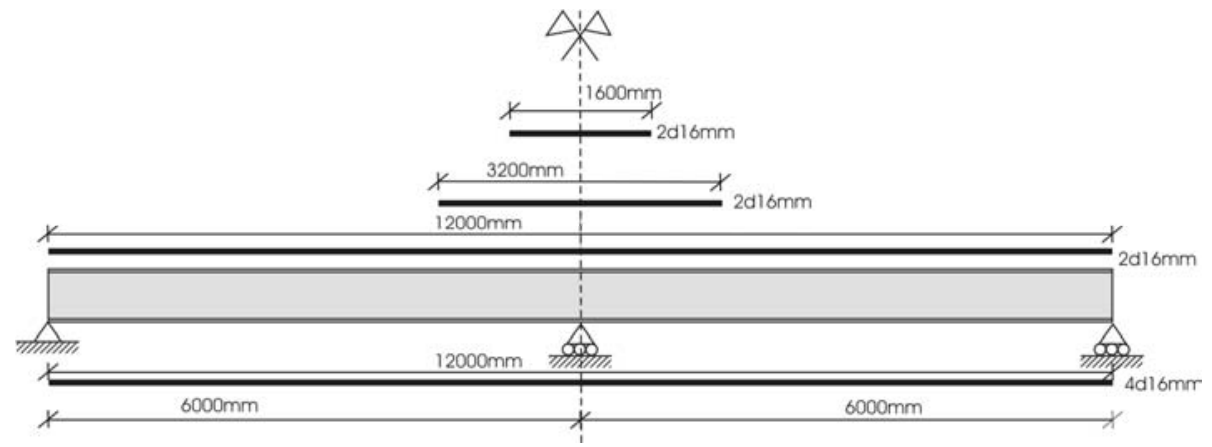

Fig. 8. Arrangement of reinforcing bars for Beam 2.

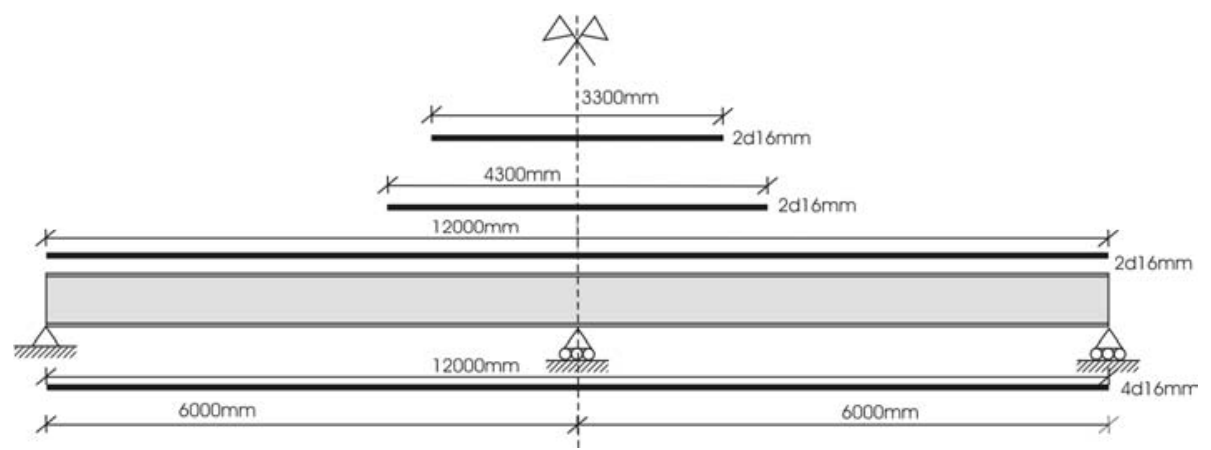

Fig. 9. Arrangement of reinforcing bars for Beam 3.

\section{Bending Moments and Deflections}

Figure 10 shows the development of the bending moment at the inner support and at the location of the maximum positive bending moment in the span for the three different beams. For all three beams, the bending moments initially increased at the centre support and consequently decreased in the spans, resulting from the tendency for thermal bowing caused by the bottom of the beam being hotter than the top of the beam. The bending moment reached its maximum at about 45 minutes, then remained reasonably constant. 
The maximum vertical displacement of the span is shown in Fig. 11. The vertical deflection increased linearly until about 95 minutes, then increased rapidly after the reinforcing bars yielded and plastic hinges started to form. The time to failure was very similar in all three beams, about 106 minutes.

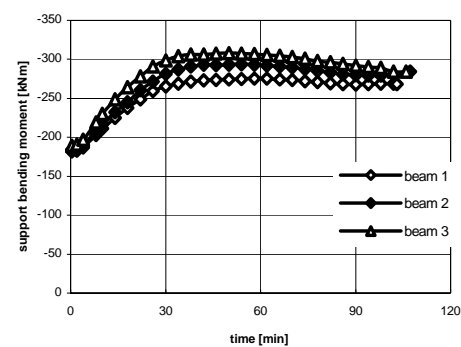

(a) At support.

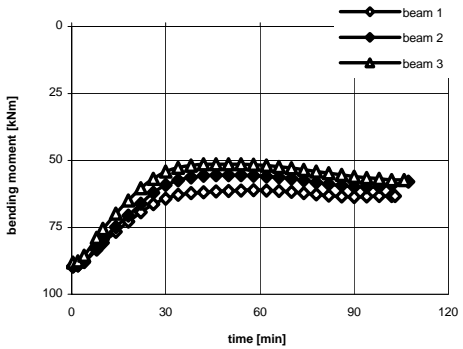

(b) At location of maximum positive moment.

Fig. 10. Development of the bending moment with time.

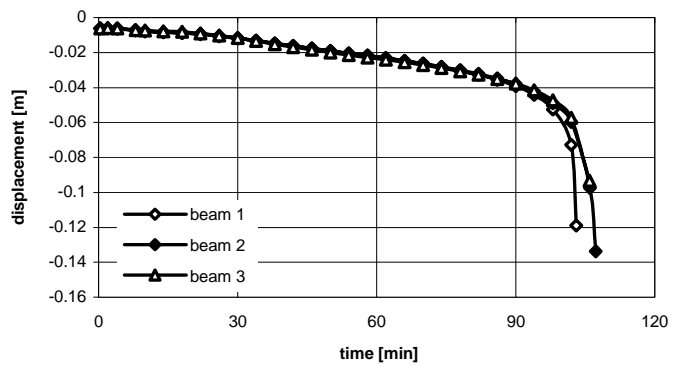

Fig. 11. Vertical displacement at location of maximum positive moment.

The deflected shape of Beams 1 and 3 at failure are shown in Fig. 12 and Fig. 13. It can be seen that the central section of Beam 1 (Fig. 12.) acted like a cantilever over the inner support, with the plastic hinges forming at the termination points of the top reinforcement (points (a)). In Beam 3 where the top bars were longer, one plastic hinge occurs directly over the central support.

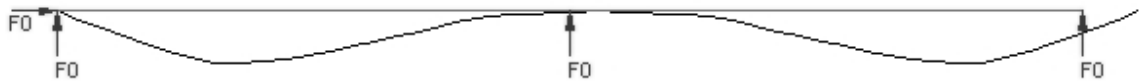

Fig. 12. Deflected shape of Beam 1 at failure.

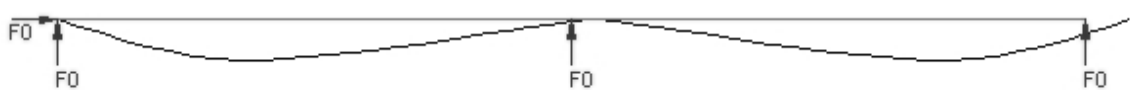

Fig. 13. Deflected shape of Beam 3 at failure. 


\section{Stresses in the Reinforcing Bars}

As an example, the stresses in the reinforcing bars of Beam 2 are shown in Fig. 14 and Fig. 15 and compared with the proportional limit and yield stress, both of which decrease with increasing temperature. The stresses for the other two beams showed similar behaviour. The stresses in the top bars at the centre support increased linearly in tension and reached their proportional limit after a short period of fire exposure (at about 20 minutes) (point (a) in Fig. 14) due to the increasing bending moment. Bars 4 and 5 started to yield in tension whereas the stresses in bar 3 stayed slightly below the yield limit.
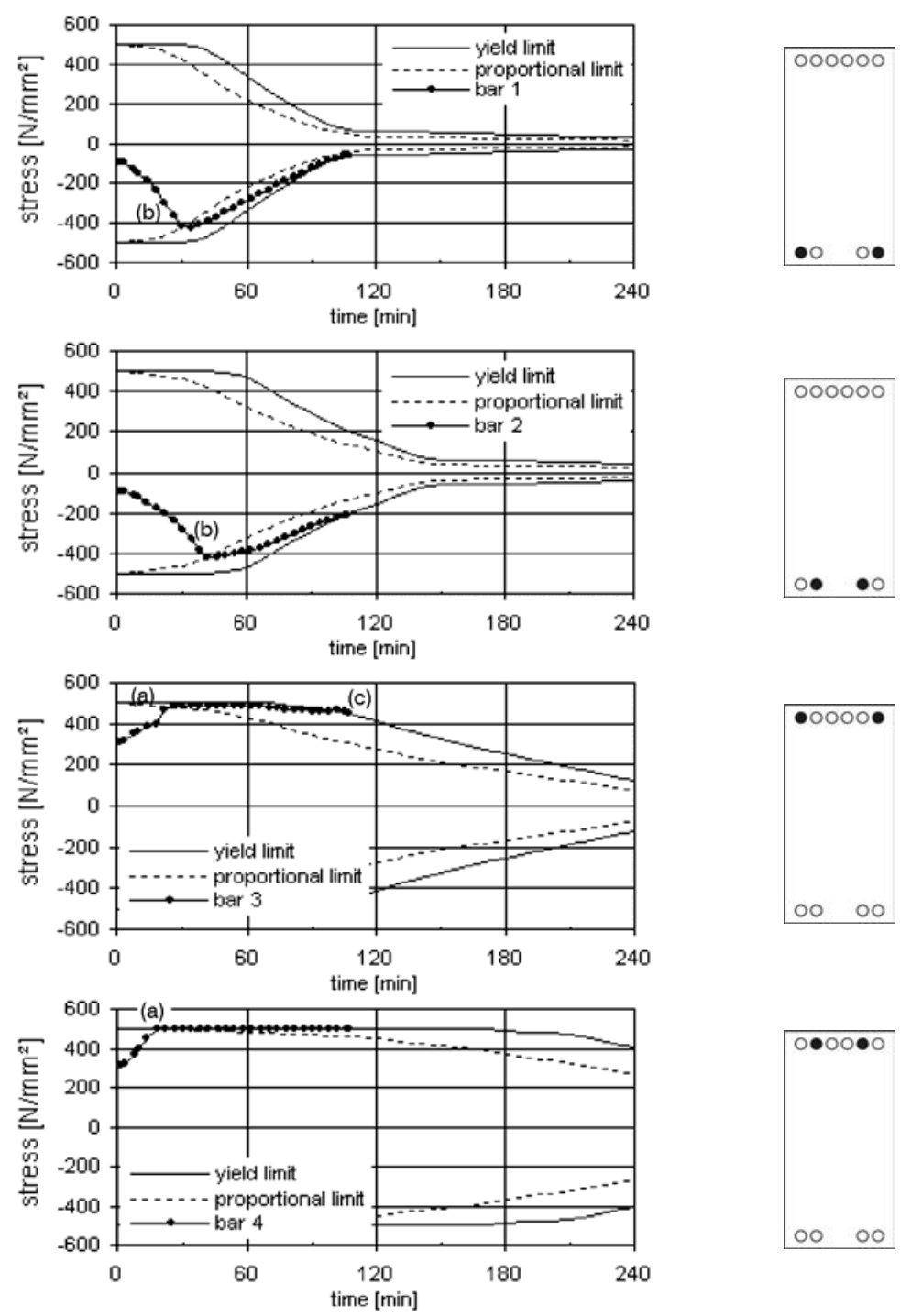

Fig. 14. Stresses in reinforcing bars at centre support for Beam 2 (tension positive). 

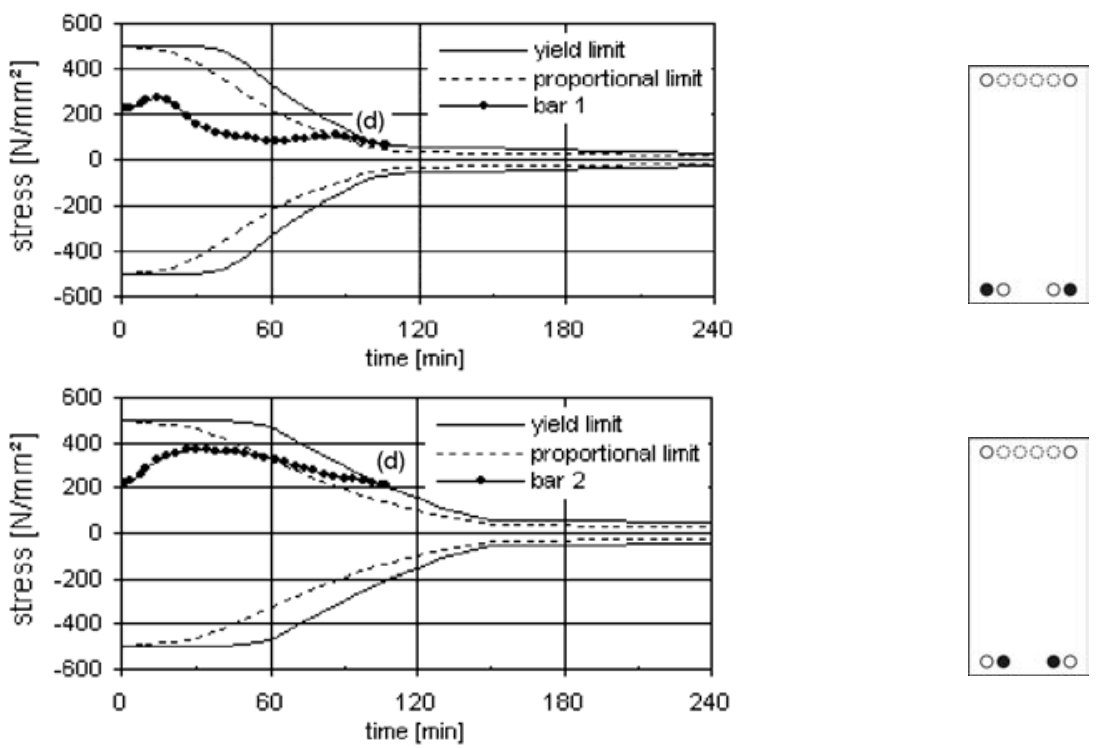

Fig. 15. Stresses in reinforcing bars at location of maximum positive moment for Beam 2 (tension positive).

The stresses in the bottom bars at the support increased in compression until they exceeded the proportional compressive limit at 30 to 40 minutes (points (b) in Fig. 14), but this did not show any influence on the still increasing bending moment. The more rapid increase in compression of bar 1 is due to the thermally induced strains.

The bottom bars in the span initially showed tensile stresses which increased as the fire progressed, although the bending moment decreased. This increase was due to the thermal expansion of the outer layers of the beam, putting them into compression, as the inner colder parts did not expand at the same rate. These compressive stresses had to be compensated by the steel bars.

When a plastic hinge started to form in the span, the redistribution of the bending moment to the support led the top bars to yield (point (c) in Fig. 14). Failure occurred when the bottom bars in the span yielded in tension (points (d) in Fig. 15) leading to a plastic collapse mechanism.

\section{Tabulated Data}

According to the tabulated data of Eurocode 2, Beams 2 and 3 have a fire resistance rating of 120 minutes. Following the rules of DIN 4102-4, Beam 3 also has a fire resistance rating of 120 minutes. These ratings could not be verified by the analysis as all three beams failed after about 106 minutes in the simulation. The simplified calculation method given in Annex E of Eurocode 2 [3] using the temperature profiles given in Annex A also predicted a fire resistance rating of less than 120 minutes.

\section{Axial Restraint}

Due to the relatively poor behaviour of the continuous beams, additional analyses were carried out with the horizontal movement of Beam 2 being restricted by an axial restraint spring. This was done in order to be more representative of real structures where the 
columns and other parts of the structure not affected by the fire could provide some axial restraint. The two springs were arbitrarily given $1 \%$ and $25 \%$ of the axial stiffness of one bay of the analysed beam. The time to failure mode increased to 209 minutes for the beam with $1 \%$ spring stiffness and 214 minutes for the beam with $25 \%$ spring stiffness, both far exceeding the tabulated fire resistance rating of 120 minutes. This suggests that in a complete frame, the bending resistance of the columns could provide sufficient axial restraint to the beams to significantly increase their fire resistance above the Eurocode rating.

\section{Single-bay Beam}

A similar analysis was carried out for a simply supported beam over a $6.0 \mathrm{~m}$ span. The beam failed after 87 minutes exposure to the standard fire when the bottom bars yielded in tension leading to formation of a central plastic hinge. Additional analyses with varying levels of axial restraint increased the fire resistance to over 90 minutes, and over 120 minutes in some cases [2]. The effect of axial restraint on fire resistance depends greatly on the height of the line of action of the restraint force, as discussed by Lim et al. [16].

\section{Three-bay Beams}

Further analyses were carried out with continuous beams over three $6.0 \mathrm{~m}$ bays. The behaviour was similar to the two-bay beams, the fire resistance being largely independent of the length of the top bars over the supports. With no restraint, the time to failure was slightly less than for the two-bay beams, and significant improvements were obtained when axial restraint was provided.

\section{Summary}

Table 1 gives a summary of the results of the analyses. It can be seen that changing the cut-off lengths of the top reinforcing bars makes very little difference to the failure times for two bay and three bay continuous beams. It can also be seen that considerable increases in failure times result from provision of modest levels of axial restraint from the surrounding structure. Additional analyses were carried out for single span beams with full flexural continuity at each end and various levels of axial restraint, leading to excellent behaviour with generally no failure during the 240 minute simulation.

Table 1. Comparison of failure times (minutes) for various conditions.

\begin{tabular}{|l|c|c|c|}
\hline & Single-bay & Two-bay & Three-bay \\
\hline No top bars & 87 & - & - \\
\hline Short top bars & - & 103 & 94 \\
\hline Medium top bars & - & 107 & 96 \\
\hline Long top bars & - & 106 & 99 \\
\hline 1\% axial restraint & 95 & 209 & 141 \\
\hline 25\% axial restraint & 137 & 214 & 175 \\
\hline
\end{tabular}




\section{Decay Phase}

Additional analyses were carried out with a decay phase after 30,60 or 90 minutes of ISO 834 fire exposure. Behaviour was very similar to the previously described behaviour. Structural failure only occurred if the fully developed phase of the fire continued until very close to the failure time reached with no decay phase. For beams which did not fail, the vertical deflections of the beam largely recovered when the beam cooled after the fire, but high levels of residual tensile stresses remained in some of the reinforcing bars.

\section{CONCLUSIONS}

This paper describes 2D finite element analysis of continuous reinforced concrete beams exposed to fire on three sides.

- Two-bay and three-bay continuous beams have greater fire resistance than a similar single span beam.

- Provision of a small amount of axial restraint (as available in most real structures) gives a very significant increase in fire resistance of continuous beams.

- For continuous beams, bending moments over the supports increase during fire exposure as a result of thermal bowing and moment redistribution.

- If the desired failure mechanism is a plastic hinge directly over the supports of continuous beams, it is necessary to lengthen the top reinforcing bars beyond the lengths suitable for ambient conditions. If the bar lengths are not increased, plastic hinges occur at the points where the bars are terminated, leading to different failure mechanisms, but no significant changes in fire resistance.

- For realistic fires with a decay phase, structural failure only occurs if the fully developed phase of the fire continues until very close to the failure time reached with no decay phase.

- This study identified some minor inconsistencies in Eurocode 2, where calculations using the simplified method predict fire-resistance ratings less than the values in the tabulated data. The SAFIR predictions were close to the results of the simplified method. This discrepancy is not a serious problem in real buildings because a small amount of axial restraint will greatly increase the fire resistance, as described above.

\section{REFERENCES}

[1] Buchanan, A.H., Structural Design for Fire Safety, John Wiley \& Sons, Chichester, 2001.

[2] Bernhart, D., "The Effect of Support Conditions on the Fire Resistance of a Reinforced Concrete Beam,” Diploma Thesis, University of Karlsruhe, Germany, and University of Canterbury, New Zealand, 2004.

(Also available as Fire Engineering Research Report 04/5 at http://www.civil.canterbury.ac.nz/fire/fe_resch_reps.html ).

[3] Eurocode 2, Design of concrete structures. prEN 1992-1-2 part 1.2: General rules - Structural fire design, European Committee for Standardization, Brussels, 2002. 
[4] Eurocode 2, Design of concrete structures. ENV 1992-1-2 part 1.2: General rules - Structural fire design, European Committee for Standardization, Brussels, 1995.

[5] DIN 4102-4 (März 1994), Brandverhalten von Baustoffen und Bauteilen: Zusammenstellung und Anwendung klassifizierter Baustoffe, Bauteile und Sonderbauteile; Deutsches Institut für Normung e.V., Beuth Verlag, Berlin, 1994.

[6] Eibl, J., Ergänzungsband zum Betonkalender 2002, Ernst \& Sohn, Berlin, 2002.

[7] DIN 4102-22 Entwurf (November 2003), Brandverhalten von Baustoffen und Bauteilen: Teil 22: Anwendungsnorm zu DIN 4102-4; Deutsches Institut für Normung e.V., Beuth Verlag, Berlin, 2003.

[8] Deutsches Institut für Bautechnik, DIBt-Richtlinie zur Anwendung von DIN V ENV 1992-1-2 in Verbindung mit DIN 1045-1, DIBt-Mitteilungen, 2/2002.

[9] CRSI Concrete Reinforcing Steel Institute, Reinforced Concrete Fire Resistance, Concrete Reinforcing Steel Institute, Chicago, 1980.

[10] Harmathy, T.Z., Fire Safety Design and Concrete; Longman Scientific \& Technical, Essex, England, 1993.

[11] Report No. ACI 216R-81, "Guide for Determining the Fire Endurance of Concrete Elements,” American Concrete Institute, 1981.

[12] FIP Commission on fire resistance of prestressed concrete structures, "FIP/CEB Report on methods of assessment of the fire resistance of concrete structural members," Fédération Internationale de la Précontrainte by the Cement and Concrete Association, Wexham Springs, 1978.

[13] Wade, C., "Method for Fire Engineering Design of Structural Concrete Beams and Floor Systems," BRANZ (Building Research Association of New Zealand), Technical Recommendation No: 8, 1991.

[14] Franssen,J.M.;Kodur,V.K.R.;Mason,J., USER'S MANUAL FOR SAFIR 2001 free, A Computer Program for Analysis of Structures submitted to the Fire, University of Liège, 2002.

[15] Eurocode 3, Design of steel structures. draft prEN 1993-1-2 part 1.2: General rules - Structural fire design, European Committee for Standardization, Brussels, 2002.

[16] Lim, L., Buchanan, A.H. and Moss, P.J., "Restraint of Fire Exposed Concrete Floor Systems,” Fire and Materials, 28:95-125 (2004). 